\title{
INTRODUCTION
}

This is the twenty-sixth issue of UNIDO's annual publication, the International Yearbook of Industrial Statistics. The Yearbook succeeded the Handbook of Industrial Statistics which was published biennially by UNIDO up to 1992. At the same time, it replaced the United Nations' Industrial Statistics Yearbook, volume I (General Industrial Statistics), which was discontinued after its 1991 edition published in 1993. These changes were in accordance with the recommendations of the United Nations Statistical Commission at its twenty-seventh session, namely that UNIDO, in collaboration with the Organisation for Economic Co-operation and Development (OECD), assumes responsibility for the collection and dissemination of world-wide general industrial statistics, effective 1994. The present Yearbook pertains to the manufacturing sector only. UNIDO has also released a separate biennial publication World Statistics on Mining and Utilities 2018.

The main purpose of the Yearbook is to provide statistical indicators to facilitate international comparisons relating to the manufacturing sector. The data presented were compiled bearing in mind the requirements of international comparability and the standards for this work promulgated by the United Nations. Concepts and definitions are drawn from the International Recommendations for Industrial Statistics 2008 (Statistical Papers, Series M No.90; United Nations publication, Sales No.E.08.XVII.8) and the classification by industry follows the International Standard Industrial Classification of All Economic Activities.

The present Yearbook consists of two parts. Part I deals with the manufacturing sector as a whole (section 1.1) and with its divisions (section 1.2). Statistical indicators are presented in terms of percentage distributions, cross-country averages, ratios and real growth rates that facilitate international comparison among selected country groups and/or economies. Graphical presentations followed by a brief description of the overall trend of world industrial growth are also displayed here. In the present publication data for manufacturing divisions are arranged according to Revision 4 of ISIC at the two-digit level.

Part II consists of a series of country/area-specific tables showing detailed data on selected basic statistics that were reported by national statistical offices (NSOs) and are presented in accordance with Revision 3 or Revision 4 of ISIC.

\section{Sources and methods}

In section 1.1 of part I, manufacturing value added (MVA) was estimated in accordance with the national accounting concept, which represents the net contribution of the manufacturing sector to gross domestic product (GDP). The data on MVA and GDP were obtained from various national and international sources including the United Nations Statistics Division (UNSD), the World Bank and OECD. These sources were supplemented with estimates generated by UNIDO.

The information in section 1.2 is drawn from the UNIDO Industrial Statistics Databases obtained from official national sources. The indicators presented in tables 1.5 to 1.9 were derived from estimates of value added at constant 2015 prices. For each economy and industrial division, these value-added estimates were generated by applying production indices to the 2015 value added base weights, which in turn were generated by UNIDO from various national and international sources.

Data reported in accordance with Revision 3 of ISIC have been converted to Revision 4 of ISIC to facilitate long time series comparison and are displayed in various tables of part I. Moreover, UNIDO rebased the index numbers of industrial production (IIP) and the national accounts data at constant prices from 2010 to 2015 in 2019. Therefore, differences may arise from the conversion/rebasing and users might find discrepancies when comparing converted data of later years with data of earlier years, published in the present edition of the Yearbook.

Due to the revision of data received from external sources, there might also be differences between the data presented in the current edition of the Yearbook and those shown in previous editions. Figures with respect to population are based on the 2019 revision of data compiled by the Population Division of the United Nations Secretariat.

To facilitate the comparability of the data over time and across economies, see "Explanatory notes", UNIDO has supplemented originally reported data with information obtained from various other sources. The latter include: industrial censuses, statistics supplied by national and international organizations, unpublished data 
collected in the field by UNIDO as well as estimates made by the UNIDO secretariat. ${ }^{1}$

Except for index numbers of industrial production (IIP), the information for the countries and areas other than the OECD member countries presented in part II were compiled from: (i) the 2017 edition of the UNIDO General Industrial Statistics Questionnaires completed by NSOs; and (ii) relevant publications issued by NSOs. Information referring to OECD member countries is based on: (a) data compiled by OECD and incorporated in OECD's Information System on Industrial Statistics as well as in the UNIDO database; and (b) data derived from official sources of NSOs. With respect to production indices, data were either collected directly by UNIDO from national sources or derived from UNIDO estimates based on the quarterly IIP. In some cases annual IIP figures were obtained from official websites of NSOs.

In part II, the measures generally used are census output and census value added. Thus, the costs of non-industrial services are included in value added, whereas the receipts for these services are excluded from output. For a quick reference, appendix III to this introduction provides notes on certain aspects of the data used, and it is recommended that the reader consult them when using the Yearbook. A detailed version appears in the individual country notes in part II, which also covers deviations from the standards applied. In general, these notes are also applicable to the estimates that supplement the officially reported data.

\section{PART I. SUMMARY TABLES}

\section{Section 1.1: The manufacturing sector}

Section 1.1 comprises tables 1.1 to 1.4. Table 1.1 shows the distribution of world MVA for various regions and groups of economies at constant 2015 prices as well as at current prices.

The readers should be aware that due to variation in official exchange rates, the world distribution may change considerably, depending on the choice of the base year.

To maintain comparability over time, composition of each group of economies was kept the same throughout the period. However, due to data limitations, a number of economies listed in appendix I are not included.

\footnotetext{
${ }^{1}$ UNIDO's procedures for estimation are described in "Nowcasting manufacturing value added for cross-country comparison", Statistical Journal of the International Association for Official Statistics Volume 26 (2009).
}

China belongs to the group of emerging industrial economies. However, because of the large size of its economy, China is presented separately in tables 1.2 to 1.4 .

Table 1.2 presents the shares of selected groups of economies in world MVA and population including industrialized economies.

Table 1.3 shows real growth rates and index numbers $(2015=100)$ of total and per-capita MVA as well as values of per-capita MVA for the latest year 2018 for individual economies and for selected country groups. Data referring to country groups were based on cross-country aggregates of MVA in constant 2015 U.S. dollars.

Table 1.4 shows the percentage shares of MVA in GDP estimated at both constant 2015 prices and current prices. The data are presented by individual economies as well as by selected country groups. With respect to the selected country groups, common country samples were taken for both indicators and for all reference years.

\section{Section 1.2: The manufacturing divisions/ branches}

Section 1.2 comprises tables 1.5 to 1.10 . It focuses on the divisions of the manufacturing sector. The ISIC (Revision 4) definition of manufacturing consists of 24 divisions reported in accordance with a two-digit code.

In (i) tables 1.5 to 1.9 , Repair and installation of machinery (ISIC 33) and (ii) table 1.7, Tobacco products (ISIC 12), had to be excluded from the presentation due to data limitations. Data for China and China (Taiwan Province) are UNIDO estimates. Furthermore, a number of estimates at the country level were also generated to enable regional aggregation or to derive world totals for the latest years.

Table 1.5 shows the world distribution of the respective value added of selected divisions among selected country groups.

Table 1.6 shows the shares of developing regions and the least developed countries in the value added of all developing and emerging economies in selected divisions.

Table 1.7 shows the world's major producers in various industrial divisions as well as the major developing and emerging industrial economies in terms of value added. 
China, which is an emerging industrial economy, is presented only among major 'World' economies. However, due to data limitations, it is not presented in all industrial divisions.

Table 1.8 shows the shares of individual divisions in total MVA by country groups.

Table 1.9 shows real growth rates of value added of individual divisions, calculated for selected country groups. The reference periods are 20102015 and $2015-2018$.

Table 1.10 presents the share of female employees in total employment in individual divisions. For some economies, employment refers to number of persons engaged instead of number of employees (see appendix III of the present introduction). Only a limited number of economies have reported data on female employment at the division level.

\section{PART II. COUNTRY TABLES}

Part II comprises country/area-specific tables presenting the following selected industrial statistics: number of establishments, number of employees (or, if not reported, number of persons engaged), wages and salaries paid to employees, output, value added, gross fixed capital formation and index numbers of industrial production. All value data are presented in current national currencies. The data on these items (except gross fixed capital formation and index numbers of industrial production) relate to the last four years for which data were reported. Gross fixed capital formation refers to the last two years for which data were reported. Index numbers of industrial production refer to the period 2006-2017.

\section{Coverage of countries/areas}

The countries/areas that are presented in part II are those which reported data during the current round of the UNIDO annual compilation programme of global industrial statistics. Those countries/areas, which reported data only in previous rounds of the UNIDO compilation programme, are not included in the present Yearbook but were included in previous editions. At the beginning of part II, those countries/areas are listed together with a reference to the respective editions of the Yearbook in which their latest data were presented.

\section{Industrial classification}

The classification of industrial activity set out in the tables follows either Revision 3 or Revision 4 of ISIC, at the two-, three- and/or four-digit levels depending on the individual country's data reporting scheme. Where information was not provided in this form, the estimates are shown in the most applicable ISIC category. Aggregates for total manufacturing are included. With regard to production indices, data are arranged either in accordance with the 2-digit level of Revision 3 or Revision 4 of ISIC.

It should be noted that in several cases a figure presented for a 3-digit group does not agree with the sum of data given for the corresponding 4-digit categories. As far as possible, UNIDO resolved these discrepancies with the help of available supplementary information.

\section{Reference unit}

For most countries and areas represented, the data shown relate to the activity of "establishments" in the specified industries. Others follow the concepts of "kind-of-activity unit", "local unit" or "enterprise". An "establishment" is ideally a production unit that engages, under a single ownership or control, in one, or predominantly one, kind of activity at a single location; for example, workshop or factory. A "kind-ofactivity unit" differs from the establishment in that there is no restriction with respect to the geographical area in which a given kind of activity is carried out by a single legal entity. A "local unit", on the other hand, comprises all activities carried out under a single ownership or control at a single location and differs from the establishment-type of unit in that there is no restriction on the range of these activities. An "enterprise" is a legal entity possessing the right to conduct business in its own name; for example, to enter into contracts, own property, incur liability for debts, and establish bank accounts. An enterprise may own one or more establishments.

Specific information on the character of the units covered in the tables for each country is set out in the corresponding country note.

\section{Reference period}

The statistics in the tables relate, in general, to the calendar year. It should be noted, however, that in many cases where the basic reference period of the industrial inquiry is the calendar year, returns covering proximate fiscal years may be accepted for reporting purposes and the data for these years incorporated in the calendar-year aggregate without adjustment. In a few countries, fiscal years normally used for public accounting purposes have been adopted as the basic reference periods. In the case of fiscal-year coverage, the year indicated in the tables refers to the calendar year in which the major part of the fiscal year falls. In the case of fiscal years from 1 July to 30 June, the year referred to is normally the one in which the fiscal year ends. 


\section{Concepts and definitions of the items}

The United Nations standards that have been applied in preparing the tables are set out below. All values are in national currency units and are at current prices unless otherwise indicated. Deviations from these concepts and definitions are described in the respective country notes.

\section{(1) Number of persons engaged and number of employees}

The number of persons engaged is defined as the total number of persons who worked in or for the establishment during the reference year. However, home workers are excluded. The concept covers working proprietors, active business partners and unpaid family workers as well as employees. The figures reported refer normally to the average number of persons engaged during the reference year, obtained as the sum of the "average number of employees" during the year and the total number of other persons engaged measured for a single period of the year. The category "employees" is intended to include all persons engaged other than working proprietors, active business partners and unpaid family workers. In this publication, preference has been given, whenever possible, to employees over persons engaged.

\section{(2) Wages and salaries}

Estimates of wages and salaries include all payments in cash or in kind made to "employees" during the reference year in relation to work done for the establishment. Payments include: (a) direct wages and salaries; (b) remuneration for time not worked; (c) bonuses and gratuities; (d) housing allowances and family allowances paid directly by the employer; and (e) payments in kind.

Compensation of employees is equivalent to wages and salaries plus employers' contributions on behalf of their employees paid to social security, pension and insurance schemes, as well as the benefits received by employees under these schemes and severance and termination pay.

\section{(3) Output}

The measure of output for many countries is based on census concept that covers only activities of an industrial nature. The value of output in the case of estimates compiled on a production basis comprises: (a) the value of sale of all products of the establishment; (b) the net change between the beginning and the end of the reference period in the value of work in progress and stocks of goods to be shipped in the same condition as received; (c) the value of industrial work done or industrial services rendered to others; (d) the value of goods shipped in the same condition as received less the amount paid for these goods; and (e) the value of fixed assets produced during the period by the unit for its own use. In the case of estimates compiled on a shipment basis, the net change in the value of stocks of finished goods between the beginning and the end of the reference period is also included.

Gross output is equivalent to census output plus the revenue from activities of a non-industrial nature. Valuation methods differ from country to country. An increasing number of countries are reporting at basic prices, which exclude taxes on commodity and include commodity related subsidies. Other methods of reporting valuation are: (a) at factor costs, which exclude all indirect taxes falling on production and include all current subsidies received in support of production activities; and (b) at producers' prices, which include all indirect taxes except VAT, or any other deductible taxes and exclude all subsidies.

\section{(4) Value added}

Value added is defined as the value of output less the value of input. Items covered in the latter include: (a) value of materials and supplies for production (including cost of all fuels and electricity purchased); and (b) cost of services received (mainly payments for contract and commission work and repair and maintenance work). If input estimates are compiled on a "received" rather than on a "consumed" basis, the result is adjusted for the net change between the beginning and the end of the period in the value of stocks of materials, fuel and other supplies.

Total value added is the national accounting concept. It is ideally represented by the contribution of the establishments in each branch of activity to the gross domestic product. Whenever census concept is applied, for the measure of total value added, the cost of nonindustrial services is deducted and the receipts for non-industrial services are added to census value added.

The estimates, whether in terms of census value added or total value added, are gross of depreciation and other provisions for capital consumption, unless otherwise stated. The valuation may be at factor costs, at basic prices or at producers' prices, depending on the treatment of indirect taxes and subsidies as described above.

\section{(5) Gross fixed capital formation}

Gross fixed capital formation refers to the value of acquisition of fixed assets including the work done on own-account during the reference year, less the value of corresponding disposals. The fixed assets covered are those (whether new or used) with a productive life of one year or more. Major additions, alterations and improvements to 
existing assets, which extend their normal economic life or raise their productivity, are also included.

New fixed assets include all those that have not been previously used in the country. Thus, newly imported fixed assets are considered new whether or not used before they were imported. Used fixed assets include all those that have been previously used within the country.

Transactions in fixed assets include: (a) cost of land purchase and land improvement; (b) dwellings, other buildings and structures; (c) machinery and equipment including transport and ICT equipment; and (d) intellectual property products, such as products of research and development, computer software, databases, etc. However, national practice may vary in terms of including these items. For example, data derived from OECD's database refer to Gross investment in tangible goods only.

Assets acquired from others are valued at purchasers' prices, which cover all costs directly connected with the acquisition and installation of the items for use. Imported assets are included only after it is acquired by the establishment which intends to use it.
In principle, assets produced on own account are also valued in this manner. However, it may frequently be necessary to value such ownaccount production at explicit cost, including any imputations that may be required in respect of the employed own-account labour.

Assets produced by one establishment of a multiestablishment enterprise, for the use of another establishment of the same enterprise, should be valued by the receiving establishment as though purchased from outside the enterprise. Sales of assets should be valued at the actual amounts realized rather than at book values.

\section{(6) Index numbers of industrial production}

Most of the national indices are calculated using the Laspeyres formula and a combination of volume extrapolation and deflation methods These methods are described in the International Recommendations for the Index of Industrial Production 2010, United Nations. In the present Yearbook the base year for comparison is 2015 . However, if any country uses different base years, the national indices are converted to the comparison base year. The theoretical aim of the IIP is to reflect the volume movements of goods or services produced over time. 
UNIDO - 9781789905717 